\title{
Kicking against the pricks: two patients wish to end essential insulin treatment
}

\author{
Roger Higgs Case conference editor
}

\section{Case conference editor's note}

\begin{abstract}
The following two cases were presented by medical students to a medico-moral case conference at King's College School of Medicine and Dentistry on 26th September 1983. Both cases are real, with some details altered to ensure anonymity.
\end{abstract}

\section{Case 1}

A 33-year-old man was admitted from prison in diabetic ketoacidotic coma. He had been diabetic since the age of twenty and had maintained himself on daily insulin injections since his late teens. He had no obvious complications of his condition, except that on some occasions his diabetic control became less satisfactory, probably due to drinking alcohol. He had a number of hypoglycaemic attacks over the three months before his admission. He worked for himself as a painter and decorator and lived with a girlfriend in South London. One month before his admission he was arrested and charged with the murder of 'one of his girlfriend's best friends'.

During his period in custody he had twice attempted to cut his wrists. It appeared also that his girlfriend was too shocked to visit. He declined his insulin injections both in the cell and in the medical wing, and gradually became more hypoglycaemic. When admitted to hospital he was semi-conscious and did not resist treatment, which included intravenous infusion and insulin.

On the ward, once stabilised, he did not object when he was given his insulin by the nurses. In conversation, however, he declared that he was innocent, and that he felt he had been deserted by his girlfriend, family and friends and did not want to live any longer. He gave strong hints that he would refuse further treatment when returned to prison, but this time 'more effectively'. He seemed determined rather than depressed.

\section{Case 2}

A 68-year-old male diabetic teacher who had been maintained on insulin injections since he was 30 developed severe diabetic complications. He was almost blind with retinal disease, had autonomic neuropathy causing irremediable diarrhoea, had early renal failure and gross arterial disease of the legs $\stackrel{\oplus}{-}$ Because of the latter, he had had a below-knee amputation on the left, and was finally readmitted with a rapidly deteriorating infected gangrene of the righe foot. His diabetes was out of control. His wife hade recently died and his children were in Australia. $\mathrm{He}_{-}$ was cared for intensively by neighbours, district nurses and the local practice team. However, he had mades himself unavailable for several days, having said he waș 'going away with friends', and had been eventually found by a persistent home help.

On the ward the infection was controlled and ${ }_{00}$ diabetes stabilised but there was no chance that his $\mathrm{f}^{+}$ could be rescued. He was faced with the need further surgery. This he refused, and instead stateids that he had 'had enough' and asked the consultant to order the staff to stop giving him his insulin.

\section{Commentary 1}

Victor Parsons King's College Hospital and Dulwich Hospital, London

I think the first patient poses the more difficult problem. Ethical decisions are a consensus of what people are conventionally doing in medicine at the $\mathbb{\Phi}_{-}^{\mathbb{D}}$ moment, and have to be to some extent both situational 3 . and contemporary, stemming from what we can do: today, in this hospital, with what we have. In mediaeval situations with mediaeval philosophy the outcome might be different. The three questions which are asked are what can we do, does what the patient wants enter into it, and on either count or both ought we to do it?

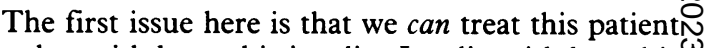
who has withdrawn his insulin. Insulin withdrawal is ${ }^{\omega}$ quite common in gestures for help and can be seen in the accident and emergency department quite often. If the patient is epileptic into the bargain what he or sheof will usually do as well is omit the antiepileptic tablets, so you have a patient with epilepsy and diabetic coma. You ought to treat this patient, however this situation $\vec{\Phi}$ has come about. In other words, the fact he has come $\frac{?}{\mathbb{P}}$ from prison makes not the slightest difference. Wounds are dressed, as Ambrose Paré said, however 
sustained, even if it is the enemy and you really dislike the person, his habits and ethics. Although there is no suggestion of that here, you still have to look after him and dress his wounds, and we are bound to look after him and bring him back to consciousness. If he then threatens to do this again, we then investigate his motivation. One of the things that ethicists talk about a lot is the freedom to choose - we must not threaten his autonomy. But no matter what the risk to yourself as doctor, whether the patient has hepatitis or lassa fever, you will treat him in spite of this risk.

However, if he threatens to withdraw his insulin again we then say 'Is he thinking correctly'? Now, we are told here that he is determined. He may be determinedly angry and determinably depressed and I think it is a very difficult thing to say about a first attempt (we are not told that he has made previous attempts but it is possible, he being an alcoholic) that there is a real continued desire on his part to die.

Once you have seen the patient (and this is one of the crucial things in the National Health Service), once the patient has actually sat down in a chair as a new patient and you have started to write about him, that is totally different from us worrying about some abstract or distant ethical problem, such as our duties towards Ethiopia or towards the people with renal failure in Southern England. We may actively participate in a debate and discuss, but when we are actually faced with a patient and we begin to take care of him there is a contract set up. 'I am now your doctor and there are a team of people around you and we are going to look after you, and looking after you does not only mean getting you out of coma, but also that I am on your side against the feelings of self-destruction.' You then say to yourself, is this man being represented correctly? Is he entitled to legal advice so that he can be defended against this charge of murder? And if he consistently feels that a return to prison will lessen his chance of a fair trial or if he is going to have a policeman sitting by his hospital bed to remind him of this, are you going to provide protection for him until he feels safe to return to the prison hospital where he will be looked after well by prison nursing staff and visiting doctors? Only when I was happy about that would I let him go; I would keep him in hospital until the legal support he was entitled to had been provided.

When we look at the second patient who withdrew his insulin, we ask does this add up to a suicide attempt, or is this a patient who is saying quietly 'enough is enough'? His physical burdens are severe, his grief over his wife's death is still weighing on him and his debt to his neighbours is increasing.

As an in-patient, the 68-year-old blind diabetic would become a double amputee and would have to be cared for long-term on a long-stay ward, probably for some months. In other words, we are condemning this patient to live longer, to suffer further. He's got fine neighbours who run around him, but a double amputee is not easy to rehabilitate in the community with all the goodwill in the world. He will probably need two people to lift him in and out of bed and they will need a lot of training. He is not keen on further surgery and further treatment - the situation in one sense is solved if the patient refuses to have his leg amputated. Two things can then happen. He will either die of septicaemia in about ten days, or the leg will mummify in the most amazing way and drop off. I have seen this happen on several occasions - it is found in the bed. I think this man will die of septicaemia, because he's elderly and a diabetic and is likely to have skin sepsis. And the chances are that an operation will be impossible and he will die. I'm afraid this happens from time to time in the wards of this hospital. Patients refuse to have their limbs taken away and quite rightly so. There is no indication here to withdraw his insulin therapy deliberately. The patient says 'I didn't put my insulin in', and he develops coma next day and then he'll find both medical and nursing staff will say 'We're very sorry, we've got to give you some insulin now, whatever you say'. I think it is keeping a contract with this particular patient to say 'Look, we shall make life as bearable as possible for you even though you are going to suffer with this septic leg, but we are still going to give you your insulin'.

Certainly we have had similar situations in renal failure. One eighteen-year-old decided against bilateral below-knee amputation. He had walked the streets of London evangelising everyone and everything for three whole days and three whole nights and he had worn his feet sore. His friends had bound up his feet and induced bilateral gangrene and he went on preaching for another three days until he was admitted in renal failure and sepsis. We said we were afraid we'd have to take his legs off, and he said 'No, you can't, I'm going to get better'. As soon as he said that we realised that he wasn't thinking correctly and we managed to find a psychiatrist to section him under Section 29 of the Mental Health Act and the surgeons came along and having taken away his freedom, amputated his legs. He recovered, got better and on the whole he was grateful although he went through a long period of psychiatric illness. There is no evidence of that sort of thing happening in this diabetic man at all, although I would certainly get advice from a psychiatrist about treating his organic depression. Where patients refuse to have their blood urea brought down by dialysis (much as this man refuses to bring down his glucose with insulin) we have bought time with antidepressants.

I had a woman with a gangrenous arm on dialysis. She refused to have this arm amputated, it led to septicaemia and she died. Three psychiatrists saw her but refused to invoke the Mental Health Act: in other words we just watched this woman die of the complications she had chosen. I was quite sure she was severely disturbed but the psychiatrists said she was just obsessional. In the end she saw animals and ants crawling all over her, but no one would section her. Those three psychiatrists refused to take away her freedom so that I could take her arm off and have 
another survivor. I was upset about that. We must recognise the anger that patients' autonomy evokes in a doctor whose help is refused.

Similarly, at the other extreme, we have had a woman who was a blind diabetic and suffering similar complications in her feet and hands who requested, and her own doctor and her own family requested, that dialysis should cease. We allowed her to die because of incipient gangrene, and because we didn't want to remove her legs and hands, thinking that was far worse than death. As you know, Rachel Rosser at Charing Cross has been able to assess the suffering that patients perceive, not just as doctors see it. This helps us to make judgements when we have got patients into a situation which they see as worse than dying. I think this is one of just those situations, where this patient perceives that his solitariness and multiple disability will probably be worse than dying. We don't know about his family in Australia - I am a bit unhappy that they haven't been talked to. It doesn't take long to phone up Sydney to get in touch with them and find out whether there may be legal and other ramifications around this patient. What we need is time to assess the family response. It may be farewell and goodbye, but we don't know.

\section{Commentary: 2}

David Marsden Institute of Psychiatry and King's College School of Medicine and Dentistry, London

It seems to me that the two cases pose different problems. In the first case, the thing that strikes me about this young man is that we really don't know what the background to the murder was. First of all, we don't know whether he may have conducted the murder in a state of hypoglycaemia. There are some clues in the history to say that he had been suffering from hypoglycaemic attacks. And it is curious that it was his girlfriend's best friend that he killed. Of course, people can act totally irrationally in a state of hypoglycaemia, with total or patchy amnesia subsequently. We are not given any information about the circumstances of the murder itself which may be, I think, crucial to the decision one is going to think about making in relation to his final request. The second thing is that the patient is obviously in a state of acute emotional disturbance subsequent to the act that he is alleged to have committed.

From my contact with murderers, whom I see from time to time at the request of psychiatrists at the Maudsley Hospital, who service Brixton Prison, such patients, and they are patients, are exceedingly difficult to categorise into any formal psychiatric diagnosis. This question of 'determined' rather than 'depressed', in these circumstances, is relatively irrelevant.

True depression, unless it was the actual cause of the murder in the first place, is not really a diagnosis that forensic psychiatrist॰ often apply to patients in a state of acute remorse after committing an act of this nature.
Having gained realisation of what they have actual done, whether in conscious knowledge, or wheth learning subsequently that they have undertake something like this in a post-epileptic automatism, of hypoglycaemia, or after a head injury, the commo $\overrightarrow{7}$ reaction of the individual is one of acute disastrous remorse rather than frank depressive illness. While this condition of acute remorse the patient is not in state to make rational decisions about his or her ow life.

Threats of suicide by murderers after committing murder are frequent. And this state of remorse may las; for a matter of months or years, although the intensity of the remorse gets less and less. For example, a patierip with neurological problems who, when his busines collapsed, eventually decided that he would get rid himself, all his children and his wife. He set about doing that and succeeded in murdering his children failed with his wife and failed with himself. This mais then made repeated attempts to try to commit suicide while in prison, but now several years later he is back again living with his wife. Although they will obviously never forget the events that occurred, he and his wif are reconciled, and are pursuing an existence which both of them find satisfying to some degree, despite his continuing neurological disease. So my own view ô this patient is that he is in a state of understandable remorse after what he has done. We don't know thashe is guilty in law of what is alleged, and I would like to know a great deal more about the circumstances ofin event before I would even contemplate any of wishes he has expressed. Like Dr Parsons, I think thi is a situation when one would keep the patient i⿱⺈ hospital under supervision until all the variou manifestations, legal, medical and otherwise had bee $\vec{B}$ clarified to the extent that he could face the consequences of his crime and be returned to prison? So, my conclusion about that man would be not accede to his wishes and certainly not to let him out of hospital until the various measures that I have suggested had been undertaken.

The second patient, I think poses a very differety. problem. As Dr Parsons has pointed out, here is tragic man who has suffered a whole collection of insults to his body which, in his eyes, make life intolerable. One has to wear two hats looking at this case: the hat of the individual himself who clearly has. the right to decide what he wants to do in these circumstances, and the hat of the doctor looking after him who has to make up his own mind whether he 8 going to be, effectively, the executioner. The patierite himself has every right to refuse surgery. Provided he is not seriously psychiatrically ill, that right, I thinis should be acknowledged. Hence, the need, I think, for an expert psychiatrist to tell one whether or not the patient is making a valid judgement, or whether the severity of any psychiatric illness is such as to rende्क such a judgement to be at fault. If the psychiatrist says that the patient is in sound mind making a judgemein about his body and there is no way that one could fore 
an operation upon him. The likelihood then is that he will die of septicaemia. The question we are really asked though is whether we as the doctors should take positive action to kill him earlier on. That is something, as a physician, I personally cannot accede to. One of the difficulties of the hospital service, as against the private relationship of the general practitioner and the patient in his own home, is that the consultant has to order 'others' to do the job. If you want to relieve suffering by an overdose of morphia in hospital, others will be watching, looking on or actually doing the act. A whole collection of people get involved in any decision of this nature and, almost inevitably, within a group of people in hospital there will be some who disapprove of an action of this nature. This makes it impossible in the public environment in which we work to carry out acts of mercy, which I am sure have taken place in private in general practice. You cannot order a nurse to give an overdose of morphia and you cannot order a nurse not to give treatment which he or she judges to be appropriate. So in these circumstances the case is actually self-solving: I would continue to give the insulin, expecting the man to die in a fairly rapid time of septicaemia, and I would give him as much relief from his pain as was required until he died.

\section{Commentary: 3}

\section{Raanan Gillon College Health Centre, Imperial College, London}

First the caveat. Complex problems of this sort in moral philosophy, which is actually what they are, cannot, in my opinion be solved in ten minutes. I enter that caveat because what my little effort is going to be is a thumbnail sketch of the sort of way in which one might try to set about solving complex problems of this sort.

It seems to me very clear that there are two moral principles that are of crucial importance here and both have emerged in the discussions that you have already heard. The first one is the principle of beneficence, that is to say helping people. Somehow or other we all have some requirement to help people. I don't think it is an overriding requirement - it is fairly obvious that we don't have an overall and absolute obligation to help everyone that we could possibly help. If you do believe that, you are postulating a very peculiar world where you should not be sitting around here, nor doing anything else, while you could be helping people. No, it seems fairly clear that the obligation to help people is limited, but one aspect of the obligation to help stems from a particular social, contractual, or as some prefer covenantal, requirement, a particular type of obligation that you may have to particular sorts of people. Among the sorts of people that you have an obligation to help are your relatives, your children, your husband, your wife, and people with whom you are in a special relationship, for example your patient when you are a doctor. However, that does presuppose, in the case of a profession, that you are asked to help. I don't believe that you have any obligation to go spreading your help around all the potential patients in the world simply because you are a doctor. Just because you've got those skills you don't have to go around and help people whether they want it or not. The assumption is that there is some sort of contract or covenant between you and your patient.

The second important principle which seems to apply here is the principle of respect for autonomy. This is difficult. Just what is autonomy? It is certainly not mere liberty in what you might call the thin sense of the term. An animal is at liberty and is free to do what it likes - it can rush around, go and chase other animals, eat them and do whatever it wants to - in the thin sense of the word liberty (or freedom) that animal is free, at liberty. Autonomy involves liberty but it also involves some exercise of man's specific capacity, as Aristotle called it, the capacity to reason, to deliberate. Autonomy is the freedom to think, to decide on the basis of one's thoughts, and to act on the basis of one's deliberated decisions. It would take a long time to pursue this notion of autonomy fully, but let me just say briefly that people from very different positions in moral philosophy have strongly emphasised the need to respect others' autonomy. Mill, that apostle of utilitarianism, wrote a whole book on liberty which is essentially about autonomy and the importance of trying to respect autonomy. $\mathrm{He}$ is often accused of trying to square the circle in defending an obligation to respect both, liberty and utilitarianism, which is the moral obligation to maximise welfare, but there are ways in which some have tried to defend him. The other strong exponent of the notion of respect for autonomy whom I wish to mention is Kant, who is an exemplar of another position in moral philosophy, the deontological position, which is based on nonconsequentialist moral rules and principles. His whole moral philosophy rests on the need to respect others' autonomy. Moral philosophers would generally agree that respect for autonomy should be a central moral principle in our dealings with each other.

What are we to do in the particular cases before us, given that little thumbnail sketch of autonomy and beneficence? In each case we seem to have a person who doesn't want our help, thank you very much. I actually agree entirely with the conclusion of the first assessment. When the patient comes in in a near-coma, we don't know much about him. It is part of our contract with society that we set about exercising our medical skills in such emergencies. We assume that people in coma want to get out of their coma. Most people do - but not all. However, we are given further implicit information that he doesn't want to go on being treated or being brought out of coma when he returns to prison. He implies (a philosopher might say he conversationally implies) that when he comes back again he'd rather we left him to die but doesn't say so. I think it is very interesting that we have had evidence 
that for us a moral 'let out' is necessary. We cannot just say ' Oh well, all we have to do is help people. There is an ill person, therefore we must set about exercising our skills'. We have to have some sort of moral let out to absolve us from our need, implicitly acknowledged, to respect that person's autonomy. One let out is to say he hasn't asked us (specifically) not to treat him. Another is to say he hasn't got enough autonomy to respect. Clearly, people do sometimes fall into that category. It seems clear to me that an unconscious person hasn't got any autonomy. But that is not to say that therefore one mustn't respect his previously expressed autonomous decision (assuming it is an autonomous decision) that when he is in that position, he doesn't want to be revived. That is the whole basis of the current efforts in California towards the living will, the desire that people should be allowed to determine in advance the way doctors should be allowed to behave towards them when they turn up unconscious in hospital. But as doctors, with presuppositions that we should save lives, we have to be reasonably sure that it is the person's autonomous decision that we should not treat him, that we should let him die. I think there is considerable doubt in the first case.

Also, in my opinion, the principle of autonomy may be justifiably overriden when people are just not mature enough to be considered to have autonomy. Young children are an obvious example. Now, they may seem as though they have got autonomy, and you can be deceived by this. My six-year-old child has got the beginnings of autonomy perfectly clearly evident. But I'm doubtful, when she says she wants to wear this or that, for instance, that it is an autonomous decision, in that she can't deliberate about it very much - 'I just want it'. It's more akin to the sort of 'decision' that an animal makes faced with two alternatives, meat on the one hand and corn on the other. If it is a carnivore it goes for the meat, if it's a pigeon it goes for the corn. That is the sort of thing from which children develop as they gradually gain more and more of this capacity to deliberate and to make their choices within some scheme of deliberation: and as a matter of pedagogy I think it's an excellent principle to treat young children as though one were respecting their autonomous choices, for that's how they gradually learn to make them. But beneficence in their case must take priority in any important matter. I don't think there are any simple ways of deciding when someone, as it were, has crossed this line. I certainly don't think it is to do directly with age. And I certainly don't think it is to do directly with having a label - depression, anxiety, remorse, youth - or any other label one is sometimes faced with as a justification. But, I am sure equally that all those things may be relevant in trying to assess whether a person is autonomous or not.

In both the cases given, I think the person's autonomy is in doubt. Furthermore for all doctors, when they are actually faced with a clinical situation, their implicit obligation to save life must be a very powerful one - certainly it is powerfully entrenched i our social organisation. So, they must be very carefut before they abandon this obligation under pressure from talk of 'autonomy'. That said, I think doctors. sometimes go too far the other way, and I do believe that in these circumstances, and indeed in at circumstances, the assumption should be that we trea⿳亠 people in medicine the same way as we treat theris throughout the rest of our society. We assume, unles there are powerful reasons to the contrary, that they ares autonomous and we must have a strong reason, even if they are threatening their lives or something of that sort, to try and justify why we should regard them as not autonomous. Often, and I think regrettably, it i the other way round. In the play Who's Life Is $\bar{B}$ Anyway? a sculptor has become paraplegic after a nast $\$$ accident. He just doesn't want to go on living, and tha itself is regarded by his psychiatrist as evidence that h is not autonomous, that he isn't 'competent', as the lawyers put it, to make decisions on his own behalf. $\$$ was perfectly clear in the play that he was competent to make his own decisions. He just didn't want to be the different sort of person that his paraplegia had mads him, even if it were true, as the psychiatrist told himo that in years to come he would be pleased that he had been turned or bent, or grateful in retrospect for the decision made on his behalf. In such circumstangesp one has to ask oneself very carefully 'Is this a genfine lack of competence such that this person doesn't em reach the minimum level of autonomy that requiresuls to respect it?' And before making that decision w should ask ourselves suppose we weren't doctors wit a special power over patients, but just ordinaro individuals faced with a person's own clearly expressed decision that he didn't want things done to him - eve? life-saving things - what should we do? Now, I thin 5 we would be very careful and we would err on the sides of caution, but ultimately if it was clear that he wasi making a firm, decided and deliberated decision tha this was the way he wanted to be treated, that his wanted to be left alone, then I think we should respec. that decision. And I think the same applies to the case we're considering. While I have doubt about both needing more information, the whole picture of the second story makes it sound as though his decision is more clearly an autonomous decision than the other'

Finally, one word about what was said abou․ whether the doctor would be a 'murderer' if he withdrew the insulin. As I see it the giving of ats injection to a person who doesn't want it is analogous 8 operating on him: it just involves rather less of injury, rather less of an assault on a person than the assault of surgery. Not only is one not obliged to carre out assaults - even life-saving assaults - on people whe reject them - on the contrary the presupposition should be that one must not assault people without their request or permission - and that includes th assault of injecting them with chemicals.

That's my outline. It doesn't give a firm decisiog about how I would deal with these particular cases 
because, as the doctors who are in hospital practice have said, one cannot tell from the inadequate information given what the circumstances are so far as their autonomy is concerned. My suspicion is that I would doubt it in the case of the first one and I would want to investigate it very thoroughly before finally respecting his autonomy (if I thought that he was autonomous); and in the second case it sounds very possible that he is autonomous, but I would still want to investigate to confirm this. Both cases may well be severely clinically depressed or otherwise severely mentally ill and the opportunity of bringing them out of depression and then letting them make autonomous decisions may be available. So I am hedging my bets; but what I am trying to do is show you the principles that $I$ would use in coming to a decision.

\section{Commentary: 4}

\section{Ian Kennedy King's College London}

You will notice a difference in the way that Raanan Gillon approached the problem of the two questions, from perhaps the approach of the two clinicians. I will adopt Raanan's approach.

Our role is to try to arm you with a toolkit of principles or schemes for analysis. We are not in the business, those of us who are professionals in the field of analysis and medical ethics of giving you answers to specific problems so that you can go out and the moment you are confronted with $\mathrm{Mr}$ Brown five years from now, who has got $\mathrm{X}$ complaint, you can pull out a plug, and say 'Under no circumstances. That's it. No more treatment. Tell the nurse and we can all go and have a drink for half an hour rather than agonising about it'.

Our job is quite the opposite - it is to annoy you, in a sense, by thrusting back on you the ultimate decisionmaking, because, after all, you are in the trenches, you have got to do the treating. Our job is to try to give you a scheme for analysis, a framework of principles, a framework of rules, a framework of ideas, so that you can carry your toolkit of intellectual insights and then open it out when you have a problem presenting itself, so that you can analyse it in abstract terms and say this is an autonomy problem, or this is a justice problem, or this is a beneficence as against a maleficence problem. Those are rather grand notions but they are part of the vocabulary that we speak and our job is to translate that vocabulary into words which you are comfortable with, so that you can then go out and use and apply them to your specific cases. You have heard Raanan Gillon say that both of these problems throw up the same tension. Very significantly high in our ranking of what we think is important is respecting other people's decisions and respecting the idea that they may carry out their decisions, respecting, in other words, their autonomy, their ability to self-rule, (that's what it means, to rule oneself). Why do we respect this principle? Largely, because we believe that people are the best judge of their own interests. You wouldn't want someone to tell you how to vote, or whom to marry, or which bus to catch. You would rather leave that to your own judgement and equally we say that if that's true in that context, so it should be true in other contexts. It is a good test for yourself as a doctor to confront someone who is making a decision which seems to you rather odd and say to yourself 'Well, that's a bit odd - but what if he knew about the things that I do? What would he think about my decisions? Would he say "That's a bit odd that you believe in so and so, or you want to do so and so"?' Would I want him to interfere with those views, even if he found, for example, that every Sunday morning I bathed the poodle for two hours, regardless of any obligation to the family, or to spouse, or to my work, that it was a must and I got terribly tight in the throat for the rest of the week if I hadn't done it. He might say 'You're out of your mind. Let me rearrange your life for you'. But you would reply 'No, because even though it seems slightly odd, that is the way that I like it'. So, if you turn this notion of respect for other people's views around and ask yourself whether you would like him, the patient, to start interfering with how you would like to run your life, then you have a good insight into how important to us is this notion of respecting other people's autonomy.

This principle applies in both cases under discussion. We are talking about a young man, and an old man, both of whom seem, at least prima facie, to have made some decision or arrived at some decision that they want to 'check out'. Therefore, that is the first principle, that is the first thing you take out of your kit-bag of principles and say, this is an autonomy problem. The next is the doubt whether it is really an autonomy problem or whether there may be other things complicating matters, such as the possibility that this man is not really autonomous, is not capable of being autonomous, because he is either irrational, or is suffering from mental illness, or is in pain, or whatever else. Do we, therefore, have to decide for him because he cannot decide for himself? But what are the justifications for doing this? We meet another principle, the idea of desire/obligation to do the best for people, the principle of beneficence. It seems that the two principles may come into conflict with each other, because what we think his decision means for him is something that we do not think will be best for him, or in his best interest - at least as regards the young man, although not in the case of the older man. There is a certain age discrimination in this problem, 33-year-old people are not allowed to want to die, but 68 -year-olds have only two years to go in any event!

This is the way that we approach these problems, not to give you answers, not to address ourselves exclusively to the particular facts, but rather to say that these are the kind of issues that are at large, and if you want to solve the problems, these are the further questions you have to ask. You have to elicit more facts, not to satisfy a certain voyeurism but because some facts are significant in resolving whether you 
respect one principle or another. For example, we do not know either man's name, but it is of no significance in assessing whether he is autonomous or not. If his name were Peter Sutcliffe it would be, but it is not, let us imagine. On the other hand we do not know, as was well put by Professor Marsden, whether the man in Case 1 committed the crime during a hypoglycaemic interlude, in which case he may be guilty of manslaughter by virtue of prior negligence, but not of murder. In other words, there are some facts which we need to know, and others which we do not, and the question is, why do we need to know them? We need to know them because they are relevant to the analysis. They are relevant because they cause us to understand whether a particular principle applies, or whether there are exceptions to it. The skill you have for asking questions is a function of whether you recognise what information is relevant to any analysis. Take my profession: imagine someone walks into my office asking for legal advice. No one walks into the room and says 'Look Mr Kennedy, I've got a false imprisonment problem which has just happened upon me'. They might come in and say, 'I was walking down the road, I grabbed this shopping bag, the fuzz comes up behind me and says hello, hello, hello, and I'm off in the police station before I know where I am. What should I do?' You must ask questions. You must ask legally relevant questions because you have a battery of principles and rules and methods of analysis, and you need relevant facts so as to discover whether you are dealing with false imprisonment or whether it is the opposite, namely a lawful arrest.

This is what you have to develop, the ability to ask not voyeuristic questions such as 'I wonder this, I wonder that, or (as was suggested by Dr Parsons) could I telephone Sydney?' You only call Sydney if consulting the relatives is relevant, and that is what I want to hear argued, not that you can contact them but that you ought to contact them for so and so reason. What is the relevance of contacting the relatives of a 68 year-old man, a 68-year-old man who seems capable of knowing his own mind? Arguably you only bring relatives in when you doubt the ability of the man to make a reasoned decision.

Let me quickly go through what I have said and try to apply it. As regards the first problem, while he is in hospital, he appears to be accepting treatment. He does not resist it, he is accepting all of it. So, here there is no problem about autonomy. He is exercising his power to decide, and appears competent to do so. He is given his treatment and he does not seem to be concerned about it. Why is he now changing his mind? You have no problem while he is in hospital. The problem that we were asked to focus on was the second one, the one about discharge. Do we discharge him? There were two arguments being advanced to suggest we should not. First, it was suggested that we get a psychiatric assessment of him, so that we can say he is mentally ill and thereby keep him in hospital. Secondly, alternatively, we are not sure whether he can really look after himself, he may make an unwise decision, so we should keep him until he is thinking correctly, as m Dr Parsons put it. I would worry about those words $\overrightarrow{\overline{\vec{n}}}$. 'thinking correctly'. They do have certain connotations, perhaps not always savoury. I would $\vec{\Rightarrow}$ have thought that, as regards discharging the man, $\stackrel{\vec{P}}{+}$ what we need to know are the relevant facts so that we can then inform him of them. For example, we need to know and tell him, as it was put by Professor Marsden, about the legal factors relevant to his conduct, so that $\stackrel{\varnothing}{\varrho}$ he can make a mature judgement as to whether, on the facts as he now understands them, he really does want $\vec{O}$ to stop taking treatment. The facts may be that he is guilty of manslaughter - which allows the judge to $\vec{\omega}$

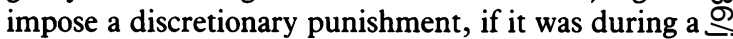
hypoglycaemic interlude - rather than of murder, $\overline{\mathrm{\Phi}}$ which carries a mandatory life sentence. So, we must, as an obligation, get the facts. Why? So as to facilitate the exercise of his autonomy by him; so as to allow him to make a considered decision. Once we have given him 오 the facts and he still says 'Well, I'm still going back to 음 prison to commit suicide', can we then say that this warrants psychiatric assessment to establish if he is mentally ill? That is a very dangerous position to take, a very dangerous one, but even if we do, and I am going to disagree with what was said before, even if we regard him as psychiatrically ill and even detain him under the Mental Health Act, we are still not entitled to treat himg without his consent, unless he is, at that point incompetent to make a decision. The mere fact thy you are categorised as mentally ill does not ipso fact mean you can never be competent. So, I am not sure that we should use the psychiatric approach. We do it because we want to be nice to him, and by being nice to him, we mean that we do not want him to commit suicide. But, if, after the facts, he makes that decision, it seems to me that we cannot undermine his autonomy by saying he is incompetent, by resorting to psychiatric devices. Alternatively, neither can we keep him in hospital until he comes round to our way of viewing things. Otherwise we would have to keep half the population in hospital until they came round to our way of thinking. Can you imagine - 'Unless you vote Tory, or unless you mend your ways, start washing three times a week or whatever, you stay in hospital'.

So, I don't think those can be the criteria. If we decide that, on the facts, he knows where he stands and he still wants to go back to prison and may well commit suicide, then I think we have to respect that autonomous decision. I am happy, however, to agree with the clinician's view, that, if he were to know the facts about his condition and the law's response to it, he would probably change his mind. If he does not, it is his mind and we ought not to regard him as mentally incompetent just because he wants to die.

Now, if we discharge him to prison, saying 'We cannot keep you any more, you're stable', he may well refuse treatment in prison and be in danger of going into a coma. What on earth do we do? The prison authorities are going to say that as they are not allowed 
to force-feed a prisoner, by analogy they are not allowed to treat him without his consent. About ten years ago the then Home Secretary, Roy Jenkins, made a decision that it was impermissible to countermand someone's decision in prison, if he wanted to starve himself to death. Bobby Sands is perhaps the best example recently. But the prison authorities do not want people to die in prison. If they say 'Take him off to the hospital', may you at the hospital, at that point, refuse to treat him? That is to me a very difficult problem, because he is in a coma now. It may depend on whether he is taken to the hospital wing of the prison or to an ordinary hospital. If it is the latter, it seems to me, (and here I agree with Victor Parsons) that the moment someone is brought in who is in a coma, you have to treat him. Even if he is a recidivist, goes in and out, in and out, you still have to treat him, because it seems to me that the obverse is to suggest that you can give up on someone because he has had his allotted number of admissions to the emergency room, such that you can say 'That is it, that's your limit'. I am not sure that I am right here, but I take the view that if he is the victim of an addictive drug or addictive behaviour or if he is in a life- or limb-threatening situation you have to treat him, even if he is a recidivist. If, however, he is engaged in playing with fire, constantly driving motorcycles at walls or jumping under buses, I think at some stage you can say 'I'm not going to treat you any longer unless you play it my way, which is to wear a crash helmet, or not to do it any longer'. In other words you may put someone on notice of future refusal of treatment if he insists on engaging in life- or limb-threatening conduct as a matter of considered choice.

Finally, what if he is admitted in a coma from the prison and it is clear to you that he wants no treatment, because he has virtually hung a notice around his neck to say 'I don't want any more treatment'? There I am with Raanan Gillon in saying that you have a statement, his last conscious statement, his last deliberative statement, and if you accept that there is no evidence of his being incompetent when he made that decision, then I think at that point you are entitled to say 'I cannot treat this person. He has denied me the permission to engage in any contract with him. I am, putting it another way, absolved of my obligation to treat him by his conscious will. He has denied me the opportunity to enter into an agreement or partnership with him'.

Now let me turn to the elderly man. He has expressed himself clearly. The question for the doctor is whether he respects the man's expression of a desire to be left alone. One option would be to allow the man to die. A second would be to undermine his autonomy by saying he is incompetent, by saying he cannot make real decisions for himself, so that we may act for him, appealing to the principle of beneficence. Thirdly, the doctor could simply overrule the man's view and act paternalistically. The doctor could say 'I hear what you say, but this is what you are going to get anyway', which is a very common practice adopted throughout life, whether we are acting as lawyers, as parents, or as doctors. I am not suggesting it is particular to any profession. Professionals tend to exert power over their client and take control. Here, it seems to me that if you reach the view that the patient is capable of being autonomous, then you respect his view. It is, then, a question for the professional whether or not to give him the insulin. The crucial feature is that he does not want any more aggressively active treatment. That is the crucial thing. Quite whether that means he should be given insulin or not, is a technical question. But I agree with Victor Parsons that your obligation is to make him comfortable and nothing more, and it is a technical matter for you whether insulin will make him comfortable. If it will you give it to him, if it will not, you do not. But you certainly do not do the surgery. He may well die.

You could, of course, regard him as incompetent by saying, either that the disease is making him incapable of making decisions or that he is making an irrational decision. Notice no one was prepared to argue that his decision to choose death was irrational whereas the younger man's decision was said to be. I think both of those courses of action are extremely dangerous, in that they undermine peoples' apparent decision-making by saying that they are in pain, or that they are under the influence of drugs, or that they are mentally ill. They allow the professional really just to say 'Well, of course I respect autonomy, but where is it here'? In other words, it would allow the doctor to override a patient's decision-making power because, in the circumstances, the patient was not capable of being autonomous. You have to be very rigorous in your analysis of the case before you undermine someone's autonomy, in my view, and just because you want to do what is right for them in your view, is not enough. Indeed that brings us to the third option, merely to ignore his wishes. But if you want to ignore them, you have to provide very good justification for so doing, because you are overriding what we think is a very important moral principle, namely respecting his individuality. The usual reason offered is that otherwise he is going to die and we can return him to some quality of life, and that is in his best interests. Well, just whose decision about 'best' is the one that ought to be the operative one? The doctor's view of what is best for him? Or the patient's view of what is best for him? If we take the view that he is autonomous, it should be his view rather than the doctor's.

The Fournal of Medical Ethics is constantly looking for examples of real medical cases illustrating moral complexities and dilemmas. It arranges for selected cases to be analysed by a multidisciplinary panel. It is also pleased to consider completed case conferences. Please contact the Editor or the Case conference editor at: Fournal of Medical Ethics, Tavistock House North, Tavistock Square, London WC1H 9LG. 